\title{
Sujeto y educación en la filosofía de la educación de Bogdan Suchodolski
}

\author{
Subject and Education in the Educational Philosophy \\ of Bogdan Suchodolski
}

MARCOS SANTOS GÓMEZ*

\begin{abstract}
Resumen: Este artículo es una exposición y análisis de la pedagogía marxista de Bogdan Suchodolski. Se ha realizado revisando sus obras principales asequibles en castellano e inglés. Se ha recurrido también a fuentes secundarias de los últimos treinta años. Se ha revisado extensamente la bibliografía. Se destacan algunos valores universales de la pedagogía de Suchodolski. Se ha mostrado también a lo largo del artículo la necesidad de estudiar distintas pedagogías en un análisis teórico, para abordar cuestiones que también afectan a la práctica, como son la antropología filosófica, la relación del educando y la historia y los fines de la educación. Este autor nos conduce a un modo de entender la educación y la pedagogía como actividades utópicas. Palabras clave: Filosofía de la educación, pedagogía, educación, marxismo.
\end{abstract}

\begin{abstract}
This article is an exposition and critical analysis of Marxist pedagogy of Bogdan Suchodolski. Revision of Suchodolski's available works translated to Spanish and English. Also, we have studied secondary sources of the last thirty years. It has been extensively reviewed the literature. We show the universal values of Suchodolski pedagogy Also, It has been shown throughout the article the need to compare different educational theories in a theoretical analysis to resolve issues that also affect practice, as for example about human nature, the relation between subject and history and goals in education. This author drives us to a way of understanding education and pedagogy as utopian activities.
\end{abstract}

Key words: Educational Philosophy, pedagogy, education, marxism.

\section{Suchodolski: una pedagogía vinculada a la historia}

El pedagogo marxista Bogdan Suchodolski (1903-1992), de la antigua Polonia comunista, nos conduce al viejo asunto en el marxismo y el neomarxismo de la conciencia y de la superestructura. Suchodolski, dentro de esta problemática teórica, pensó desde su perspectiva marxista lo que puede lograrse mediante la educación. Concretamente, reconoció,

Fecha de recepción: 06/01/2013. Fecha de aceptación final: 06/02/2013.

* Profesor Contratado Doctor en la Universidad de Granada, Departamento de Pedagogía. Su correo electrónico es masantos@ugr.es Sus líneas de investigación son la filosofía de la educación y la teoría de la educación. Entre sus más recientes trabajos publicados, se encuentran: Santos, M. (2013). «Educación, símbolo, tacto. Más allá del modelo instrumental en la pedagogía». Arbor, 189 (763): a073. Doi: http://dx.doi.org/10.3989/ arbor.2013.763n5010, y Santos, M. (2013). Educación y construcción del Self en la Filosofía Helenística según Michel Foucault, Revista Española de Pedagogía, vol. 71, nº 256, pp. 479-492. 
en la época de apogeo del socialismo real, un desfase entre los logros políticos, por un lado, y la organización del sistema educativo, por otro, lo que explicaba como herencia de la denominada por él «pedagogía burguesa» ${ }^{1}$. Su visión de lo logrado en la Polonia comunista implicaba la opinión de que todavía había un futuro por hacer y de que, en consecuencia con el socialismo, lo propio del hombre sería estar en transformación constante. Una transformación que lo sitúa como agente activo de sí mismo, y no como un mero producto de procesos históricos ${ }^{2}$.

La educación no lo es sólo para el presente sino que siempre ha de incorporar un elemento de futuro que él denomina, como Ernst Bloch, «esperanza» ${ }^{3}$. Contrapone esto a toda educación resignada con lo dado ${ }^{4}$ Es decir, un elemento de no resignación ante lo dado que ha sido recogido también, en la pedagogía, por un autor del prestigio de Paulo Freire. Tanto Bloch como Freire representan una versión cálida del marxismo (utópica y, en el caso de Freire, impregnada de elementos personalistas) que, además de ejercer una impugnación crítica de lo existente, propugna una alternativa, incluso tras la caída del Muro ${ }^{5}$. La consecuencia de esto para la idea de educación es expuesta con claridad por Suchodolski:

La educación no debería tratarse como adaptación, ni aún en el caso de una adaptación para el futuro. Debería tomar parte en todos los procesos de reconstrucción que hoy buscan una senda juiciosa que conduzca al futuro. La Educación no debería formar ni manipular a los jóvenes según unos modelos de futuros autoritarios y esquemáticos; debería despertar la fuerza que construyera el futuro ${ }^{6}$.

Esto enlaza además, en el caso de Suchodolski, con una crítica al consumismo ${ }^{7}$ e incluso con la necesidad de replantearnos nuestra noción de progreso y desarrollo desde nuevos valores ${ }^{8}$.

Sin embargo, la comparación con Walter Benjamin, para el cual la negatividad siempre presente en la historia (incluida en la triunfante sociedad socialista) es recordada por la teología (el enano jorobado de la primera tesis sobre el concepto de historia) ${ }^{9}$ pone de manifiesto lo que separa su marxismo próximo al socialismo real, de otros marxismos más críticos y alternativos. Porque a pesar de todos los triunfos y revoluciones, siempre quedará la cuenta pendiente con el pasado.

1 B. Suchodolski: Fundamentos de pedagogía socialista, Barcelona, Laia, 1976.

2 Ibíd., p. 10.

3 B. Suchodolski: «Philosophy and Education», International Review of Education, n ${ }^{\circ} 25,1979$ pp. 347-366. P. 354.

4 B. Suchodolski: «Situación de los jóvenes en la crisis: Dependencia e interdependencia». Cuadernos de Pedagogía, $\mathrm{n}^{\circ} 121,1985$, pp. 76-81. P. 76.

5 R. Van Heertum: «Marcuse, Bloch and Freire: reinvigorating a pedagogy of hope», Policy Futures in Education, vol. 4, nº 1, 2006, pp. 45-51. P. 47.

6 B. Suchodolski: «Educación para el futuro», Cuadernos de Pedagogía, nº 81, 1981, pp. 37-44. P. 37.

7 Ibíd., p. 38.

8 Ibíd., p. 39.

9 T. Lewis: «Messianic Pedagogy», Educational Theory, vol. 60, n 2, 2010, pp. 231-248. Pp. 231-232. 
En ciertos elementos, se ha mostrado fructífero el pensamiento de Walter Benjamin para la pedagogía ${ }^{10}$, un pensamiento que busca la universalidad desde «el margen» ${ }^{11}$ y que podemos relacionar con autores «proféticos» como Illich ${ }^{12} \mathrm{o}$ «mesiánicos», como el propio Freire $^{13}$. Éste y su carácter mesiánico representa una posibilidad de enriquecimiento para la pedagogía crítica de inspiración marxista, como la de Giroux o McLaren ${ }^{14}$. Además, el papel del impugnador (y esperanzador al mismo tiempo) recuerdo de las víctimas en la educación, plantea algunos interrogantes que en nuestra era postmoderna debería recoger la teoría educativa ${ }^{15}$.

Por eso, siempre hay un plus, llámese esperanza o futuro, pero este plus no puede ser definido en un sentido positivo, ya que incurriríamos en nuevas alienaciones, por lo que tanto Adorno $^{16}$ como Horkheimer prefieren mantenerse con mayor radicalidad que Suchodolski, Bloch y Freire «a la espera», en una actitud que se relaciona con la teología negativa ${ }^{17}$. No obstante, se ha insistido en que esto puede desembocar en un pesimismo de corte gnóstico, que bien puede mantener un potencial revolucionario o de impugnación a la realidad ${ }^{18}$, o bien sumergirse en actitudes fatalistas de corte schopenhaueriano, como fue el caso del último Horkheimer ${ }^{19}$.

La concepción antropológica marxista de Suchodolski lo lleva a explicar como algo patológico los típicos antagonismos «burgueses», como por ejemplo el del individuo con la sociedad. Según el pedagogo polaco, es el desfase entre los ideales y la realidad que acarreó el desarrollo del mundo burgués lo que condujo a visiones fatalistas, desesperanzadas, que pretendían superar la escisión entre lo privado y lo público, lo individual y lo social, o la naturaleza y la cultura erróneamente acentuando uno de los polos ${ }^{20}$. Esto produjo una concepción conflictiva de la existencia humana que abarcaba desde autores antiguos como Hobbes, Hume y Rousseau hasta el psicoanálisis y el existencialismo. Los ilustrados, a pesar del optimismo propio de la Ilustración, meditaron largamente esto, inmersos en la problemática emanada de sus sociedades burguesas que intentaban superar el régimen feudal.

10 Cfr. T. Lewis: op. Cit.; S. P. Vignale: «Childhood and experience in Walter Benjamin: playing at being other», Childhood \& philosophy, vol. 5, n 9, 2009, pp. 77-101. Pp. 95-100; S. Dobson: «The Pedagogue of the Auratic Medium: Extending the Argument», Journal of Philosophy of Education, vol. 42, n 2, 2008, pp. 325-331; N. Peim: «Walter Benjamin in the Age of Digital Reproduction: Aura in Education-A Rereading of «The Work of Art in the Age of Mechanical Reproduction»», Journal of Philosophy of Education, vol. 41, n 3, 2007, pp. 363-380.

11 R. Mate: «El margen de la política», Daimon. Revista de Filosofía, n 27, 2002, pp. 9-29.

12 T. Lewis: Op. Cit., pp. 234-236.

13 Ibíd., p. 236.

14 Ibíd., pp. 243-245.

15 T. Lewis: «Utopia and Education in Critical Theory», Policy Futures in Education, vol. 4, no 1, 2006, pp. 6-17. P. 16.

16 Suchodolski se refiere a Adorno en un excelente artículo dedicado a las relaciones entre filosofía y educación: vid. B. Suchodolski: «Philosophy and Education»..., p. 353.

17 I. Gur-Ze'ev: «Adorno and Horkheimer: Diasporic-Philosophy, Negative Theology, and Counter-Education», Educational Theory, vol. 55, $\mathrm{n}^{\circ} 3,2005$, pp. 343-365. P. 351.

18 Ibíd., pp. 363-365.

19 J. A. Estrada: La Teoría Crítica de Max Horkheimer, Granada, Universidad de Granada, 1990.

20 B. Suchodolski: Fundamentos... Op. Cit. p. 26. 
El punto central en la perspectiva antropológica del pedagogo marxista es que toda concepción de «naturaleza humana» ya es un reflejo de un orden concreto. Suchodolski lo expresa con claridad: «Así que no es la naturaleza del hombre, sino su existencia social, la que alumbra a la civilización y es el motor de sus cambios» ${ }^{21}$. La naturaleza humana es siempre histórica y por tanto mutable, no puede servir como fundamento para consagrar un orden social, sino que ha de darse una reconstrucción de la sociedad, superándose la sociedad burguesa del extrañamiento del hombre respecto a su propio producto, su sometimiento al mismo, para que cambien elementos de la «naturaleza humana», como el egoísmo individualista, que supuestamente nos constituyen.

\section{Educación polivalente y superación de la escisión entre trabajo teórico y trabajo práctico}

Suchodolski explica el estilo de la educación socialista según algunos textos de Marx como la formación de una nueva conciencia a partir no tanto de una educación intelectual, sino sobre todo como «el resultado de las experiencias de la acción acometida por los obreros $»^{22}$. Así, a comienzos de los años 80 incidía en la necesidad, en su país, de reforzar, junto con la educación permanente, una educación en la que estuvieran enlazados economía, sociedad y cultura en una política educativa encaminada al desarrollo de una sociedad socialista $^{23}$. No se trata en este modelo pedagógico de encarnar ideales desde arriba, sino de ir creando esos ideales durante el desarrollo de la acción.

A partir de una situación concreta surgen las condiciones para el establecimiento de fines. Pero esto no quiere decir que se actúe inmerso en la situación actual, sino que ha de establecerse también una perspectiva de futuro como motor del presente, nunca como vago ideal abstracto. Marx, como es sabido, se enfrentó a los socialistas utópicos que pecaban, según él, de este idealismo utopista de tender a un futuro ajeno e inconexo con la realidad actual. A esto subyace un interrogante planteado, en efecto, por todos los utópicos del XIX: ¿Hay que cambiar primero las condiciones sociales o primero a los hombres? En realidad, cualquier respuesta que priorice uno u otro elemento resulta errónea, según Suchodolski, pues para Marx, la polémica entre subjetivismo u objetivismo se resuelve con la síntesis dialéctica de ambos, de manera que según él las circunstancias crean a los individuos igual que los individuos crean las circunstancias. La transformación se entiende como un mismo movimiento revolucionario de individuos y condiciones que implica una forma de humanismo no idealista que supera viejos planteamientos pedagógicos que revisa en sus obras ${ }^{24}$.

Esto conlleva unas implicaciones pedagógicas concretas, como por ejemplo la vinculación con las circunstancias concretas de la vida y la acción del individuo por parte de cualquier formación intelectual o moral. Explica Suchodolski que para Marx, «El intelecto y la moral no son, ni mucho menos, unas facultades aisladas del individuo, sino la forma de

21 Ibíd., p. 32.

22 Ibíd., p. 46.

23 B. Suchodolski: «Into the 1980s: Perspectives and Prospects in Poland», Comparative Education, vol. 16, $\mathrm{n}^{\circ} 3$, 1980, pp. 303-309.

24 B. Suchodolski: «Education, Between Being and Having», Prospects, vol. 6, n 2, 1976, pp. 163-180. 
su participación en la vida social de su época y en sus aspiraciones esenciales» ${ }^{25}$. Así, a toda educación debe corresponder el conocimiento de las leyes que explican la propia realidad (naturaleza y sociedad). Se trata de una comprensión (científica) del mundo y el entorno, adquiriendo instrumentos conceptuales para vincular la propia acción con el mundo.

La educación marxista ha de formar individuos polifacéticos, multifacéticamente desarrollados, combinando estudio y trabajo ${ }^{26}$. Contra la rutinización y mecanización de las tareas propias de las formas de producción capitalistas que cosificarían y deshumanizarían al obrero (y al patrono), ahora se trata de devolver al trabajo su papel de creación y realización humana, de acción creativa, de rico intercambio con el medio. Marx destacó «(...) cómo el capitalismo había destruido el valor 'humano' del trabajo, el cual radica en que el hombre, al transformar el mundo material, contribuye a su propio desarrollo» ${ }^{27}$. El trabajo humanizado llegará entre otras cosas por el desarrollo tecnológico que evita las tareas pesadas y satisfará las necesidades básicas del hombre, por lo que se tendrá más tiempo y posibilidades de desarrollo personal (acceso universal a la «alta cultura»).

Hay una unidad dialéctica entre hombre y ciudadano. Por el contrario, como se manifiesta en Rousseau, en la sociedad capitalista hay una división trágica entre el ideal del hombre y el ideal del ciudadano. De ahí la vaguedad e idealismo que Marx denunciara en la Declaración de los derechos del hombre y del ciudadano, de corte burgués. Lo propio del mundo burgués sería, según Suchodolski, la pretensión de realizar idealmente lo que de hecho no lo está en el mundo material. Así, el utopismo resultaría encomiable por sus buenas intenciones, pero nada más. Esto lo vio, afirma, el pedagogo suizo Pestalozzi, que en la arena educativa aprendió que toda educación presupone una sociedad concreta, y por tanto, hay un límite a las especulaciones de la pedagogía más idealista.

Conviene acudir a la materialidad de lo humano que impregna también, por supuesto, a los productos culturales. Pero esta materialidad, y aquí también debemos ponernos sobre aviso, no deber inducirnos a formas reduccionistas de entender lo educativo: sociologicismo, psicologicismo, biologicismo e historicismo. Todo ello responde a la pretensión de abordar lo educacional como dato o hecho, es decir, se trata de formas de un positivismo cuya equivocación estriba en su unilateralidad. Frente a ello, el propio Suchodolski aboga por una recuperación del elemento humano en una suerte de humanismo marxista que intenta contemplar al hombre como realidad compleja y como hacedor y producto, al mismo tiempo, de la historia. Hay una actividad del sujeto que opta por ciertas transformaciones en su medio, pero en una opción consciente y consecuente, al mismo tiempo, con lo que de hecho existe en el medio.

Así, Suchodolski intenta eludir el mismo peligro reduccionista en el marxismo, aunque evitando cuidadosamente incurrir en la sobrevaloración del polo subjetivista. Su clave de bóveda es el hombre reconciliado por fin, tras los siglos de conflictos y divisiones propias de los modelos de sociedades relacionadas con antropologías dualistas. Toda educación es parte, en realidad, de una sola experiencia ligada a la realidad presente y, al mismo tiempo, va anticipando lo nuevo y transformando la realidad presente.

25 B. Suchodolski: Fundamentos... Op. Cit., p. 47.

26 B. Suchodolski: «The Future of Higher Education», Higher Education, n 3,1974, pp. 331-340. Pp. 338-339.

27 B. Suchodolski: Fundamentos... Op. Cit., p. 51. 
Pero el hombre es — por encima de todo- un ser que aspira a rebasar las condiciones de existencia imperantes, a evadirse y superar la realidad presente. En la técnica y el arte, en su actividad social, el hombre crea una realidad nueva, crea su propio mundo material, social e imaginario ${ }^{28}$.

Dentro de una concepción procesual de la existencia humana el hombre es más que la animalidad a secas, aunque la incluya sin escisiones, ya que lo animal carece de historia en el sentido en que lo humano dispone de ella. El animal humano se realiza actuando en su medio, que es natural y social, realización que a lo largo del tiempo compone una historia. Así, la educación tiene como principal instrumento el medio social, con el cual va interactuando el educando. Esto recuerda enormemente a Dewey, del que se distancia Suchodolski por la idea específicamente marxista de la historia. Pero la educación como producto de un medio ambiente (natural y social), del «diálogo» con el mismo, de la multiplicación y profundización de las experiencias que producen el conocimiento es la clave de la pedagogía de ambos. Se da una comprensión de la historia que en Dewey resulta más lineal y en Suchodolski es evidentemente dialéctica en el sentido marxista. Es esta dialéctica de la historia la que el hombre ha de ir captando, lo que resulta la mayor aspiración de la pedagogía. Para él el dinamismo humano es dialéctico, la relación que el educando manifiesta con su medio social.

\section{La unidad dialéctica de individuo y sociedad}

Según Suchodolski, la pedagogía socialista debe eludir la tendencia de la pedagogía «burguesa» a la privatización de los fines de la educación. Esto último reposa en el prejuicio liberal de que buscando fines individuales se garantizan los objetivos generales de la sociedad. Así, el sistema educativo debe ofrecer, según los sistemas burgueses, las opciones al individuo para la búsqueda de sus propios fines que consisten en un aprovechamiento y adaptación a la economía liberal y sus intereses. Por la educación liberal se buscaría un destino a los hijos que equivaldría a la aspiración particular de los padres, que tiende a la exitosa adaptación a la sociedad imperante. No hay una pretensión, por tanto, de incidencia real en la transformación de la sociedad, aunque el lenguaje pedagógico utilice conceptos como «perfeccionamiento», «progreso», «productividad» o «riqueza». En cualquier caso, se aceptaría la inmutabilidad de las condiciones sociales imperantes.

Relacionado con la perspectiva liberal y burguesa se daría un voluntarismo de la historia, que pasaría a ser la historia de los hechos, las hazañas y las grandes figuras, por un lado, o la otra forma de historia que la considera férreamente determinada por instancias sobrehumanas o condicionamientos inmutables (historicismo). Todas estas concepciones de la historia adolecen de la escisión entre lo subjetivo y lo objetivo, posicionándose sólo desde uno de los polos. El materialismo dialéctico, sin embargo, entiende el mundo como una síntesis o interrelación de lo subjetivo y lo objetivo ${ }^{29}$. De manera más precisa, Suchodolski dice que «El materialismo histórico marxista rechaza tanto la tesis de la identidad del sujeto y del

28 B. Suchodolski: Fundamentos... Op. Cit., p. 167.

29 B. Suchodolski: Tratado de pedagogía, Barcelona, Península, 1979. P. 35 
objeto como la tesis consistente en su diferencia fundamental y su oposición absoluta» ${ }^{30}$. Así, descarta tanto el concepto idealista que reduce todo a un estado de conciencia, como el materialismo grosero que suprime la libertad del hombre (Comte, Spencer, Durhkeim).

El polo subjetivista ha adoptado, según Suchodolski, una perspectiva psicológica, como de hecho ocurre en el psicoanálisis. Desde este polo, «la sociedad y sus instituciones habrían de ser el reflejo de las facultades psíquicas de los individuos, sobre todo de sus impulsos sociales» ${ }^{31}$. Así, la transformación social debería acudir a los entresijos de la psique y orientar una educación que sobre todo en la lactancia y la niñez remota produjera la constitución psicológica proclive a una forma de sociedad «sana». Aquí se peca según el polaco de eludir la realidad objetiva exterior al sujeto y no se da la interrelación entre subjetividad y objetividad que sí ofrece el marxismo. Creo que la clave de este marxismo es un concepto de acción en el que precisamente se integren ambos polos. Hay reglas objetivas al tiempo que actividad de los individuos. Esto es ilustrado por ejemplo por la técnica, que es un producto humano que a su vez transforma a los hombres. Del mismo modo, «la ciencia crea a los sabios y los sabios crean la ciencia; de esta manera, el arte crea a los artistas y los artistas crean el arte» ${ }^{32}$.

Pero a la hora de pensar al sujeto educando, su construcción, al self, creo que la opción freudomarxista incide en un elemento que el polaco parece no apreciar en su justa medida: la psique. El elemento de encarnación, la corporalidad, no me han parecido suficientemente expuestos y explicados en sus trabajos. Aunque es de notar que Suchodolski se refiere expresamente a las ricas aportaciones, a su juicio, de autores próximos al psicoanálisis y a la sociología, e incluso se refiere en alguna ocasión con halagos a la escuela Summerhill ${ }^{33}$. Muchos teóricos de la educación han defendido que el psicoanálisis, en su versión lacaniana, aporta las bases para una noción de subjetividad diferente de la subjetividad cartesiana que el marxismo, y la pedagogía en general, deberían superar ${ }^{34}$. De hecho, ha habido elementos que conectan, en cierta medida, con el psicoanálisis en autores específicamente marxistas, como Lukács ${ }^{35}$.

Lo bueno del freudomarxismo es que supera el fatalismo psicologicista de Freud pero proporciona unas claves para entender asuntos que el polaco a veces pasa demasiado por alto. La psicología como ciencia no tiene por qué implicar la necesaria adaptación a la sociedad, sino que en estos enfoques (Reich, Fromm, Marcuse) desarrolla un potencial de transformación social con excelentes aplicaciones a la educación, como es el caso de Erich Fromm ${ }^{36}$. Su concepción de enajenación que combina lo psíquico y lo social, así como su noción de

30 B. Suchodolski: Fundamentos... Op. Cit., p. 65.

31 B. Suchodolski: Fundamentos... Op. Cit., p. 66.

32 B. Suchodolski: Fundamentos... Op. Cit., p. 69.

33 B. Suchodolski: «Philosophy and Education»... Op. cit., p. 351.

34 D. Cho: «Wo es war: Psicoanálisis, Marxism, and Subjectivity», Educational Philosophy and Theory, vol. 39, $\mathrm{n}^{\mathrm{o}}$ 7, 2007, pp. 703-719.

35 Ibíd., p. 711.

36 Así lo han señalado expresamente: E. Weiner: «Paths from Erich Fromm: Thinking Authority Pedagogically», Journal of Educational Thought, vol. 37, $\mathrm{n}^{\circ}$ 1, 2003, pp. 59-76; S. Brookfield: «Overcoming Alienation as the Practice of Adult Education: The Contribution of Erich Fromm to a Critical Theory of Adult Learning and Education». Adult Education Quaterly, vol. 52, n 2, 2002, pp. 96-111; G. E. Bernen: «Moral Education and the Burden of Self-Centeredness», Independent School, vol. 43, n 1, 1983, pp. 48-53. 
«carácter social» sirven para entender cómo lo histórico (lo configurado históricamente) se halla presente en elementos de la personalidad y cómo la personalidad, a su vez, puede incidir en lo histórico ${ }^{37}$. Puede afirmarse que

Fromm es muy consciente de los problemas contemporáneos y toma posición en contra de la mercantilización a ultranza de la existencia y de la búsqueda de seguridad fuera de uno mismo, en vez de centrarse en la fuerza interior para alcanzar la libertad ${ }^{38}$.

El propio Suchodolski valora la diferenciación entre ser y tener por parte de Erich Fromm $^{39}$. Y afirma algo que suscribiría sin duda el alemán:

«El simple tener — propiedad, poder, trabajo — no es malo. Tener, simplemente por tener, tener la vida humana se convierte en un medio de ampliar las pertenencias privadas, puesto que debería ser un medio de ampliar la personalidad humana» ${ }^{40}$.

Más adelante:

La dignidad y la felicidad no están concebidas en términos de riqueza, esplendor, moda y desnaturalización, ni en la atmósfera de la lucha competitiva por el dinero, el poder, el trabajo, la explotación y el control de los demás ${ }^{41}$.

En el caso de Marcuse, al que Suchodolski también se refiere en alguna ocasión ${ }^{42}$, también se ha valorado su crítica al capitalismo y el consumismo ${ }^{43}$. De hecho, las conocidas teorías de Marcuse han tenido frecuente eco y aplicaciones en la pedagogía hasta hoy día, como ejemplifican algunos trabajos cercanos en el tiempo ${ }^{44}$.

El pedagogo polaco considera que la pedagogía socialista debería contribuir a desarrollar la capacidad de acción formando la conciencia como captación de las condiciones sociales.

37 A. K. Das: «The Dialectical Humanism of Erich Fromm», Journal of Humanistic Education and Development, vol. 32, nº 2, 1993, pp. 50-60.

38 L. Espinosa: «Contra el miedo: Spinoza y Fromm», Thémata. Revista de Filosofía, n 38, 2007, pp. 47-60. P. 58.

39 B. Suchodolski: «Educación para el futuro»... Op. cit., p. 40.

40 Ibíd., p. 41.

41 Ibíd., p. 42.

42 B. Suchodolski: «Philosophy and Education»... Op. cit., p. 354.

43 R. Van Heertum: «Marcuse, Bloch and Freire: reinvigorating a pedagogy of hope»... p. 47.

44 Vg. T. Shel: «On Marcuse and Caring in Education», Policy Futures in Education, vol. 4, n 1, 2006, pp. 52-60; S. Brookfield: «Reassessing Subjectivity, Criticality, and Inclusivity: Marcuse's Challenge to Adult Education», Adult Education Quaterly, vol. 52, n 4, 2002, pp. 265-280; Id.: «A Critical Theory Perspective on Accelerated Learning», New Directions for Adult and Continuing Education, vol. 97, 2003, pp. 73-82; Id.: «Diversifying Curriculum as the Practice of Repressive Tolerance». Teaching in Higher Education, vol. 12, $\mathrm{n}^{\circ}$ 5-6, 2007, pp. 557-568; C. Pierce: «Groundwork for the concept of Technique in Education: Herbert Marcuse and Technological Society», Policy Futures in Education, vol. 4, n 1, 2006, pp. 61-72; D. Calderón: «One-Dimensionality and Whiteness», Policy Futures in Education, vol. 4, n 1, 2006, pp. 73-82; S. Tomlinson: «Gifted, talented and high ability: selection for education in a one-dimensional world», Oxford Review of Education, vol. 34, n 1, 2008, pp. 59-74, pp. 63-64. 
Esto recuerda enormemente a la perspectiva de Paulo Freire, que insiste también muy a menudo en que los excesos subjetivista u objetivista deben superarse en la pedagogía del oprimido, huyendo de todo fatalismo o alienante impotencia en el sujeto ${ }^{45}$. Para Freire, la educación debe propiciar la comprensión y el control del medio, unificando sujeto y objeto en la misma forma que parece explicar Suchodolski. Esta alienación puede cobrar la forma (burguesa) de ir hacia un futuro que se concibe como desarrollo de los planes existenciales del individuo, ajeno a la acción de tipo social. De nuevo, uno de los principales rasgos del universo burgués es el individualismo que se escinde del conjunto social, desde el prejuicio fomentado por la economía liberal de que en la búsqueda de lo privado la sociedad obtiene su mejor configuración y va perfeccionándose.

Así, en el punto de mira de la pedagogía «burguesa» estaría solamente lo psicológico y lo metodológico-didáctico, soslayando lo social y lo histórico. Se da potestad a la ciencia para dictar los fines de la educación (falacia naturalista y positivismo), de manera que lo que realmente procede de una configuración social concreta, es elevado a una categoría supuestamente neutral. Esto acabó conduciendo a una pedagogía que sobrevalorando lo descriptivo se separa de la reflexión de tipo ético y filosófico acerca de las finalidades. Es decir, se dota a la ciencia de autoridad para dictar los fines a la pedagogía que acaba en ciencia descriptiva y, por tanto, en una disciplina que consagra lo dado. Esto es, y seguimos la exposición de Suchodolski, el proceso por el que la pedagogía se ha acabado convirtiendo en «ciencias de la educación».

En realidad, la pedagogía que busca describir (y ya nada más) adoptó tres perspectivas, para ser más exactos ${ }^{46}$ : histórica (historia de la educación), sociológica y psicológica, tendencias que en efecto, parecen hoy día ser lo propio y lo predominante en la pedagogía. El problema es que entonces la pedagogía deja de ser pedagogía, en opinión de Suchodolski, y se torna algo parecido a la medicina, que desde la descripción científica intenta alcanzar lo normativo. La pedagogía «se despolitiza» y en lugar de reflexionar sobre los fines, los proporciona de un modo técnico, prescriptivo. Pero como bien señalaba el pedagogo polaco, en educación las cosas no pueden ser como en medicina, y lo normativo se halla presente incluso en el propio método didáctico, con lo que tras la didáctica habría una apuesta, aun inconsciente, por finalidades concretas. En realidad, como nos recuerda la Escuela de Fráncfort, lo descriptivo no puede separarse de lo normativo.

\section{El futuro y los fines de la educación}

Según Suchodolski, la manera en que el Estado y la ciencia pueden hallar los fines para la educación es mediante la activación del futuro, analizando las tendencias sociales e históricas y engarzándolo en el presente como algo vivo que forme parte importante del mismo. Además, «La educación al servicio del futuro debiera, ante todo, centrar sus esfuerzos en la formación de una conciencia crítica» ${ }^{47}$. Esto promueve el desarrollo, aun cuando se considere «peligroso» por las tendencias contrarias al cambio, siendo distinto del utopismo «burgués»

45 P. Freire: Pedagogía del oprimido, Madrid, Siglo XXI, 1992.

46 B. Suchodolski: Fundamentos... Op. Cit.

47 B. Suchodolski: «Educación para el futuro»... Op. cit., p. 39. 
que peca de irrealista, y que por tanto o bien sirve como manera de eludir el presente o, aun peor, lo fuerza imponiéndole fines ajenos. Suchodolski valora la utopía en la medida en que consista en anticipar con realismo y sin escapismo ${ }^{48}$.

Como señala Jaume Trilla:

No le interesa tanto diseñar la educación del porvenir cuanto desentrañar la que ahora correspondería para contribuir a crear aquel futuro. Educar para el futuro tampoco es, según Suchodolski, educar según unos modelos de hombre y sociedad fijos y definitivamente establecidos como los que perpetraban las utopías renacentistas o decimonónicas. Educar para el futuro es, en cambio, educar hombres que puedan participar activa y comprometidamente en la génesis de un porvenir realmente deseable ${ }^{49}$.

Hay, por tanto, que ir realizando el nuevo concepto de trabajo y tarea no rutinaria del ciudadano multifacético y capaz de acceder a las bondades de la tecnología y de la cultura y el conocimiento. Esto es el verdadero humanismo, según el polaco, de un sistema para el hombre y no contra el hombre.

La perspectiva socialista estriba precisamente en la conjugación, la reconciliación de los intereses colectivos y los intereses individuales en un nivel en el que la vida del individuo ya deja de guiarse por los egoísmos primitivos, aun cuando sigue basándose en las aspiraciones individuales a realizar todas sus posibilidades y satisfacer sus crecientes necesidades ${ }^{50}$.

De este modo, en el sistema socialista se ofrecería la mayor gama de posibilidades de realización para el individuo, que dejaría de sufrir el peso de una ideología individualista burguesa que obliga a los hombres a ser seres egoístas. Ahora sí el desarrollo individual contribuiría al desarrollo colectivo, una vez que la finalidad egoísta es sustituida por la finalidad que podíamos llamar de «realización personal».

\section{Conclusión final: la tarea de la educación}

En la parte final de un excelente artículo sobre Th. W. Adorno, Jose Antonio Zamora ${ }^{51}$ advierte de que la constante exigencia de cumplir con los requisitos del mercado laboral y de una preparación técnica frenética para no sufrir la exclusión laboral tiene un efecto devastador:

supone el triunfo de la ideología economicista neoliberal en el plano de la automercantilización de los individuos, que han de estar dispuestos a relativizar sus rasgos

48 Ibíd., p. 40.

49 J. Trilla: «Suchodolski, un clásico vivo», Cuadernos de Pedagogía, n 151,1987, pp. 80-81.

50 B. Suchodolski: Fundamentos... Op. cit., p. 107.

51 J. A. Zamora: «Th. W. Adorno: Aportaciones para una Teoría Crítica de la educación», Teoría de la Educación, vol. $21, n^{\circ} 1,2009$, pp. 19-48. 
personales o incluso a no formar ninguna personalidad en el sentido clásico para adaptarse flexiblemente a las condiciones rápidamente cambiantes del mercado ${ }^{52}$.

Frente a esto, señala

Educación sería la tarea de ayudar a cuestionar esa función, la coacción social y la dominación, a negar la reducción de los individuos a categorías económicas, a desenterrar y formular por medio de un trabajo crítico negativo los propios intereses y necesidades, en los que poder reconocerse como fines en sí, evitando la falsa apariencia de una supuesta autonomía que todavía está por realizar. Educar así sería luchar contra la ilusión de una vida lograda en medio de la sociedad falsa ${ }^{53}$.

Así, la pedagogía debería, desde un enfoque crítico, cumplir una función de resistencia a estas dinámicas procedentes del mundo de la economía de mercado que están dictando sus leyes a lo educativo sin ser apenas cuestionadas. Es en este contexto que creemos que la pedagogía sería más útil si no se centrara tanto en ofrecer métodos o respuestas o competencias para un mundo dado, sino en interrogar(se), en sospechar de sus propias explicaciones y en introducir incluso elementos discrepantes y marginales en su discurso. Así cabría entender una pedagogía y por ende una escuela y universidad verdaderamente comprometidas con la sociedad, que ejercieran en ella de instancias críticas, tarea hoy más necesaria que nunca.

De la filosofía de la educación de Suchodolski se desprende, esperamos que de nuestro trabajo sea esto lo que haya quedado claro, una crítica a la idea de una educación que hoy nos llega en la forma de enseñar competencias, como hemos señalado que indica el profesor Zamora, para un mundo bien definido y no cuestionado, un mundo individualista y mercantilista que se asume como bueno sin demasiadas objeciones.

Suchodolski nos sitúa en la dinamicidad y en la impugnación como actividades propias de la pedagogía, del saber humano. Más exactamente, en un término medio, ya que no puede aceptar ni la armonía perfecta ni la conflictividad eterna. Frente a todo ello, la antropología marxista

no separa al individuo —ni en tanto que ser corporal, ni como psique, ni como ser social — del mundo que él mismo crea, sino que analiza 'el hombre y su mundo' conjuntamente, es decir, al hombre como artífice del mundo y a la vez como un ser formado por su propia obra ${ }^{54}$.

Según esto, la problemática histórica se convierte en la problemática central de la antropología y en el principal elemento de la estructura de la personalidad ${ }^{55}$. Pero Suchodolski realiza la importante aclaración de que esto no implica un determinismo por el que el hombre sería un simple producto de las relaciones sociales. El hombre responde en efecto a la realidad creada, pero al mismo tiempo es creador de ella. Desde el presupuesto de la

52 Ibíd., p. 43.

53 Ibíd., p. 45.

54 B. Suchodolski: Fundamentos... Op. cit., p. 182.

55 Ibíd., p. 184. 
constante transformación del medio donde se nutre el hombre, no hay lugar para un férreo determinismo, lo que coloca a Suchodolski en una posición en la que el propio Marx fue ambiguo pero que como educador se ve obligado a adoptar. No puede consistir la educación en la donación de un mundo hecho, sino en la donación de un mundo hecho y por hacer, al mismo tiempo. Ahí es donde se sitúa el joven y ahí es donde el factor futuro entra en acción para transformar el presente.

El medio no es un simple complejo de condiciones ante las que reacciona el individuo «autónomo». No es, propiamente, «medio ambiente». Dice Suchodolski: «El hombre no es un ser acabado que pueda reaccionar de diferentes maneras según los cambios de las condiciones históricas, sino un ser que se transforma en medio de esas condiciones» ${ }^{56}$. Es materia constituyente de aquello que podemos denominar sujeto educando. Las mutaciones históricas no significarían, entonces, nuevos entornos ante los que reacciona el sujeto neutro e intemporal, sino que es este mismo sujeto el que cambia con las transformaciones en esas condiciones históricas. «Por lo tanto, como afirmaba Marx, la naturaleza que se crea a través de la historia humana es la verdadera naturaleza del hombre y, pese a su forma alienada, es la verdadera naturaleza antropológica» ${ }^{57}$.

No hay individuo separado de su medio, sin que esto signifique la renuncia a la libertad. No hay un destino al que someterse, sino que la historia es creación de los hombres reales. La especificidad marxista, frente a planteamientos como el de Proudhon, es que no son las ideas sino los hombres vivientes implicados en las contradicciones concretas de su existencia histórica los artífices ${ }^{58}$. «La naturaleza humana es, pues, histórica no sólo porque crea la historia, sino también porque se expresa y transforma en el curso de su creación de la historia» ${ }^{59}$. Esto se encuentra en las antípodas de la concepción de la personalidad que la entiende como algo que se crea al margen del proceso histórico y a la que mueven leyes específicas de los impulsos, la adaptación, la sublimación o la frustración. También se opone a la concepción de una personalidad que se realiza mediante la realización de los valores objetivos, como pretende el idealismo y la teoría idealista de la cultura y la formación.

Lo encomiable de Suchodolski es, frente a estas concepciones, la idea de que no hay desarrollo del individuo al margen del desarrollo de su mundo. El hombre se crea creando el mundo en el que vive, lo que conduce a un proceso de incremento del conocimiento y de la complejidad del mundo.

Así, pues, la tarea fundamental de la educación debe consistir en preparar a los individuos para que sepan escoger racionalmente el camino de la vida que les permita salvar tanto los escollos del oportunismo como los del conformismo que contemplan los estados de hecho transitorios como la última y justa sentencia de la historia, así como el quijotismo que lleva a luchar estérilmente contra determinados aspectos del desarrollo histórico ${ }^{60}$.

\footnotetext{
56 Ibíd., p. 185.

57 Ídem.

58 B. Suchodolski: Tratado de pedagogía... p. 87.

59 B. Suchodolski: Fundamentos... p. 186.

60 Ibíd., p. 190.
} 
Es decir, la (buena) educación consistiría en situar a los hombres en condiciones de elegir adecuadamente su modo de vida. Esto implica una personalidad integrada que asuma la problemática específica de su propio tiempo.

\section{Referencias bibliográficas:}

BERNEN, G. E.: «Moral Education and the Burden of Self-Centeredness», Independent School, vol. 43, n 1, 1983, pp. 48-53.

BROOKFIELD, S.: «Reassessing Subjectivity, Criticality, and Inclusivity: Marcuse's Challenge to Adult Education», Adult Education Quaterly, vol. 52, n 4, 2002, pp. 265-280.

-: «Overcoming Alienation as the Practice of Adult Education: The Contribution of Erich Fromm to a Critical Theory of Adult Learning and Education», Adult Education Quaterly, vol. 52, no 2, 2002, pp. 96-111.

-: «A Critical Theory Perspective on Accelerated Learning», New Directions for Adult and Continuing Education, $n^{\circ} .97,2003$, pp. 73-82.

-: «Diversifying Curriculum as the Practice of Repressive Tolerance», Teaching in Higher Education, vol. 12, no 5-6, 2007, pp. 557-568.

CALDERÓN, D.: «One-Dimensionality and Whiteness», Policy Futures in Education, vol. 4, no 1, 2006, pp. 73-82.

CHO, D. Wo es war: Psicoanálisis, Marxism, and Subjectivity. Educational Philosophy and Theory, vol. 39, nº 7, 2007, pp. 703-719.

DAS, A. K.: «The Dialectical Humanism of Erich Fromm», Journal of Humanistic Education and Development, vol. 32, $\mathrm{n}^{\circ} 2,1993$, pp. 50-60.

DOBSON, S.: «The Pedagogue of the Auratic Medium: Extending the Argument», Journal of Philosophy of Education, vol. 42, n 2, 2008, pp. 325-331.

ESPINOSA, L.: «Contra el miedo: Spinoza y Fromm», Thémata. Revista de Filosofía, ${ }^{\circ}$ 38, 2007, pp. 47-60.

ESTRADA, J. A.: La Teoría Crítica de Max Horkheimer, Granada, Universidad de Granada, 1990.

FREIRE, P.: Pedagogía del oprimido, Madrid, Siglo XXI, 1992.

GUR-ZE'EV, I.: «Adorno and Horkheimer: Diasporic-Philosophy, Negative Theology, and Counter-Education», Educational Theory, vol. 55, n 3, 2005, pp. 343-365.

LEWIS, T.: «Utopia and Education in Critical Theory», Policy Futures in Education, vol. $4, \mathrm{n}^{\circ} 1,2006$, pp. 6-17.

—: «Messianic Pedagogy», Educational Theory, vol. 60, n 2, 2010, pp. 231-248.

MATE, R.: «El margen de la política», Daimon. Revista de Filosofía, n 27, 2002, pp. 9-29.

PEIM, N.: «Walter Benjamin in the Age of Digital Reproduction: Aura in Education-A Rereading of «The Work of Art in the Age of Mechanical Reproduction»», Journal of Philosophy of Education, vol. 41, n 3, 2007, pp. 363-380.

PIERCE, C.: «Groundwork for the concept of Technique in Education: Herbert Marcuse and Technological Society», Policy Futures in Education, vol. 4, nº 1, 2006, pp. 61-72.

SHEL, T.: «On Marcuse and Caring in Education», Policy Futures in Education, vol. 4, n ${ }^{\circ}$ 1, 2006, pp. 52-60. 
SUCHODOLSKI, B.: «The Future of Higher Education», Higher Education, nº 3, 1974, pp. 331-340.

—: Fundamentos de pedagogía socialista, Barcelona, Laia, 1976.

—: «Education, Between Being and Having», Prospects, vol. 6, n 2, 1976, pp. 163-180.

—: Tratado de pedagogía, Barcelona, Península, 1979.

—: «Philosophy and Education», International Review of Education, $\mathrm{n}^{\circ} 25,1979$, pp. 347366.

—: «Into the 1980s: Perspectives and Prospects in Poland», Comparative Education, vol. $16, \mathrm{n}^{\mathrm{o}} 3,1980$, pp. 303-309.

—: «Educación para el futuro», Cuadernos de Pedagogía, nº 81, 1981, pp. 37-44.

—: «Situación de los jóvenes en la crisis: Dependencia e interdependencia», Cuadernos de Pedagogía, no 121, 1985, pp. 76-81.

TOMLINSON, S.: «Gifted, talented and high ability: selection for education in a onedimensional world», Oxford Review of Education, vol. 34, nº 1, 2008, pp. 59-74.

TRILLA, J.: «Suchodolski, un clásico vivo», Cuadernos de Pedagogía, n ${ }^{\circ}$ 151, 1987, pp. 80-81.

VAN HEERTUM, R.: (2006). «Marcuse, Bloch and Freire: reinvigorating a pedagogy of hope», Policy Futures in Education, vol. 4, nº 1, 2006, pp. 45-51.

VIGNALE, S. P.: (2009). «Childhood and experience in Walter Benjamin: playing at being other», Childhood \& philosophy, vol. 5, n 9, 2009, pp. 77-101.

WEINER, E.: (2003). «Paths from Erich Fromm: Thinking Authority Pedagogically», Journal of Educational Thought, vol. 37, $\mathrm{n}^{\circ}$ 1, 2003, pp. 59-76.

ZAMORA, J. A.: «Th. W. Adorno: Aportaciones para una Teoría Crítica de la educación», Teoría de la Educación, vol. 21, nº 1, 2009, pp. 19-48. 